\title{
Both Induction and Morphogenesis of Cyst Nematode Feeding Cells Are Mediated by Auxin
}

\author{
Aska Goverse, ${ }^{1}$ Hein Overmars, ${ }^{1}$ Jan Engelbertink,${ }^{2}$ Arjen Schots, ${ }^{2}$ Jaap Bakker, ${ }^{1}$ \\ and Johannes Helder ${ }^{1}$ \\ ${ }^{1}$ The Graduate School for Experimental Plant Sciences, Laboratory of Nematology, Wageningen University, \\ Binnenhaven 10, 6709 PD, Wageningen, The Netherlands; ${ }^{2}$ The Graduate School for Experimental Plant \\ Sciences, Laboratory for Monoclonal Antibodies, Wageningen University, Binnenhaven 10, 6709 PD, \\ Wageningen, The Netherlands \\ Accepted 7 June 2000.
}

\begin{abstract}
Various lines of evidence show that local changes in the auxin concentration are involved in the initiation and directional expansion of syncytia induced by cyst nematodes. Analysis of nematode infections on auxin-insensitive tomato and Arabidopsis mutants revealed various phenotypes ranging from complete inhibition of syncytium development to a decrease in hypertrophy and lateral root formation at the infection site. Specific activation of an auxin-responsive promoter confirmed the role of auxin and pointed at a local accumulation of auxin in developing syncytia. Disturbance of auxin gradients by inhibiting polar auxin transport with $N$-(1-naphthyl)phtalamic acid (NPA) resulted in abnormal feeding cells, which were characterized by extreme galling, massive disordered cell divisions in the cortex, and absence of radial expansion of the syncytium initial toward the vascular bundle. The role of auxin gradients in guiding feeding cell morphogenesis and the cross-talk between auxin and ethylene resulting in a local activation of cell wall degrading enzymes are discussed.
\end{abstract}

Cyst-forming nematodes of the genera Heterodera and Globodera have the potential to induce the formation of feeding cells by refined intervention in the developmental program of the host plant. Preparasitic second-stage juveniles (J2) enter the root preferentially at the elongation or differentiation zone. Juveniles migrate intracellularly toward the vascular cylinder. Depending on the nematode-host combination, a differentiated or nondifferentiated root cell is preferred as starting point for feeding cell induction (Magnusson and Golinowski 1991 and literature cited therein). The morphology and ultrastructure of syncytia is basically the same irrespective of the nematodehost plant combination. Feeding cell formation is presumably initiated in response to signal molecules released by the infective juvenile (reviewed by Williamson and Hussey 1996).

Very early in feeding cell development, cell wall openings between the initial syncytial cell and adjacent cells are formed. Initially, cell wall breakdown occurs by a gradual widening of plasmodesmata; later, large openings are created without the involvement of these natural cytoplasm bridges (Grundler et

Corresponding author: Aska Goverse; Telephone: +31 317485086; Fax: +31 317484254; E-mail: aska.goverse @ medew.nema.wau.nl al. 1998). Progressive cell wall dissolution results in the expansion of the feeding cell toward and within the stele along the xylem vessels. Subsequent fusion of the protoplasts results in a hypertrophied multinuclear cell complex, a syncytium, that can include up to 200 cells (Jones 1981). The central vacuole of the cells is replaced by numerous small, secondary vacuoles and the dense cytoplasm contains numerous organelles and enlarged nuclei. Extensive cell wall protuberances are formed at those parts of the syncytium that are in close contact with xylem elements. These protuberances greatly enlarge the plasma membrane surface, thereby facilitating massive short-distance nutrient import that is essential for nematode development. The hypertrophic feeding cell is lined by a thickened cell wall to resist the osmotic pressure that increases up to 9,000 to $10,000 \mathrm{hPa}$ (Jones and Northcote 1972; Böckenhoff and Grundler 1994).

When the starting point of syncytium formation is a pericycle or (pro)cambium cell, feeding cell establishment coincides with lateral root formation. This was observed for the oat cyst nematode (Heterodera avenae) on wheat (Grymaszewska and Golinowski 1991) and the beet cyst nematode (H. schachtii) on rape (Magnusson and Golinowski 1991) and Arabidopsis thaliana (Sijmons et al. 1994). Lateral root formation is initiated in pericycle cells, which are arrested in the $G_{2}$ phase of the cell cycle. Feeding cell development is apparently accompanied by the stimulation of neighboring pericycle cells to reenter the cell cycle. This progression in the cell cycle is controlled by cyclin genes in combination with $c d c 2$ genes (Doerner 1994). In young root parts of A. thaliana, the cell cycle regulating protein kinase $c d c 2 a$ was shown to be expressed all over the pericycle (Hemerley et al. 1993). Niebel et al. (1996) detected $c d c 2 a$-gus expression upon cyst nematode infection not only in young but also in older root parts where $c d c 2 a$ is normally not expressed. Exogenous application of auxin to roots not only resulted in a great rise in the number of lateral root initials, but also increased the expression of the mitotic cyclin gene cyclAt (Doerner et al. 1996). Infection of $A$. thaliana roots with beet cyst nematodes resulted in strong cyclAt::gus expression in very young synctia only. Apparently, lateral root initiation and syncytium formation have a number of characteristics in common. This is further illustrated by large-scale screening of promoter trap lines, which resulted in a relatively high proportion of genes that 
was expressed both in lateral roots and in nematode feeding cells (Scheres et al. 1997). Strong auxin-insensitive mutants, such as the tomato mutant diageotropica ( $d g t)$, fail to form lateral roots, and it would be interesting to see how parasitism is affected by this kind of response mutant.

In this article, evidence is provided that auxin plays a prominent role in the early stages of feeding cell development by cyst nematodes. The role of auxin was demonstrated by using phytohormone mutants from tomato and A. thaliana inoculated with either potato cyst (Globodera rostochiensis) or beet cyst $(H$. schachtii) nematodes. In vitro, the tomato mutant $d g t$ was shown to be de facto resistant to potato cyst nematodes. Further evidence for the role of auxin was demonstrated by transcriptional activation of the auxin-responsive promoter trap line 826 and aberrant feeding cell morphogenesis as a result of the application of the auxin transport inhibitor $\mathrm{N}$-(1naphthyl)phtalamic acid (NPA). The role of a localized disturbance of the auxin levels is discussed in relation to feeding cell formation by cyst nematodes.

\section{RESULTS}

Early feeding cell development is restricted in the auxin-insensitive tomato mutant $d g t$.

Under in vitro conditions, the auxin-insensitive tomato mutant $d g t$ is de facto resistant to the potato cyst nematode $G$. rostochiensis (Fig. 1). Penetration and migration in the roots of the mutant $d g t$ was normal, but the majority of the parasitic $\mathrm{J} 2$ were unable to develop into adult females (Fig. 2A and B). Only one female developed on $d g t$ after inoculation of approximately $50 \mathrm{dgt}$ roots. Nematodes infect roots, preferably just behind the root tip. The mutant $d g t$ lacks lateral roots and, therefore, the number of available infection sites is reduced. To correct for this potential bias, a fixed number of nematodes (approximately 50) was added to an equal number of root tips from both $d g t$ and the control cv. Moneymaker. Inhibition of nematode development was not the result of an abnormal morphology of the $d g t$ roots. In cross sections, the roots of $d g t$ and Moneymaker were virtually identical. Only the number of xylem elements in $d g t$ was slightly higher and somewhat com-

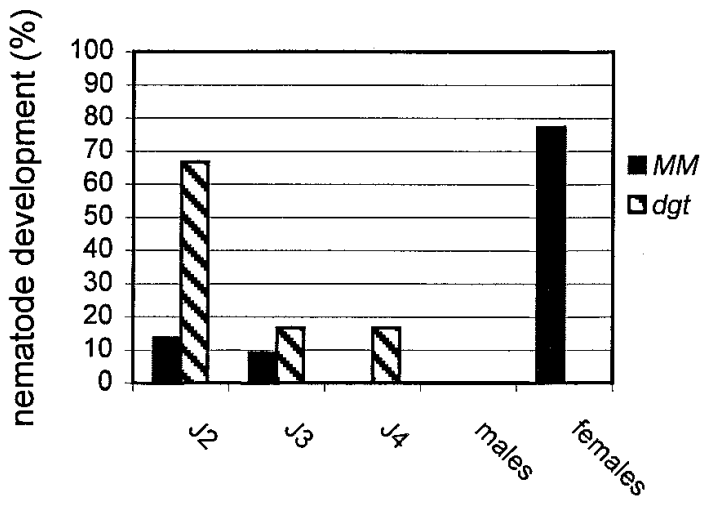

Fig. 1. In vitro potato cyst nematode development on roots of the auxininsensitive tomato mutant diageotropica (dgt) and its corresponding background cv. Moneymaker (MM). Nematode development was expressed as the percentage of parasitic second-stage juveniles (J2) that had continued their development (to J3, J4, or adult female) at 49 days postinoculation. The data presented are from one representative experiment out of three with comparable results. pressed compared with that in Moneymaker. This phenomenon has been described for the $d g t$ shoot by Zobel (1974).

A similar though less-pronounced effect was observed for infected plants grown under greenhouse conditions. Nematode development, expressed as the average number of cysts per plant, was significantly reduced by $71 \%$ in $d g t$ roots $(126 \pm 23$ [mean $\pm \mathrm{SD} ; n=3]$ ) compared with the Moneymaker control $(441 \pm 110 ; n=4)$. Cysts formed on $d g t$ were slightly smaller and the average number of eggs per cyst was reduced by approximately $25 \%$. To see whether a hampered feeding cell proliferation could underly the poor development of the nematode, infected roots of $d g t$ and Moneymaker were sectioned at different time intervals. Both in $d g t$ and Moneymaker, the parasitic J2 were found with their stylet inserted into the initial syncytial cell. Syncytium induction started in the outer cortex and radial expansion toward the stele was observed at 3 and 6 days postinoculation (dpi). However, a complete degradation of the cytoplasmic content was observed in the majority of the feeding cells induced in $d g t$ (Fig. 2C and D). Mitotic activity - which usually occurs in cells surrounding the developing syncytium in Moneymaker-was also observed in $d g t$. Occasionally, poorly developed females were observed in $d g t$ encapsulated by the root. This strongly points at a malfunctioning feeding cell, characterized by a less extreme response: cell wall breakdown was severely hampered, resulting in small feeding cells containing enlarged nuclei. This structure was lined by a thickened cell wall. Extensive callose deposit, metaxylem differentiation, and cell division were observed in adjacent tissues (Fig. 2E and F). In the rare case that a fully developed female was found on $d g t$ roots, the length of the syncytium was halved compared with Moneymaker (data not shown). The occurrence of these abnormal feeding cells corresponds with the reduction in nematode development on roots of $d g t$ shown in Figure 1. This demonstrates that the dgt mutation obstructs early feeding cell development by cyst nematodes.

\section{Nematode development on auxin-insensitive Arabidopsis mutants.}

To confirm the role of auxin in syncytium development, a range of auxin-insensitive Arabidopsis mutants (Table 1) was inoculated with the beet cyst nematode $H$. schachtii (A. thaliana is a nonhost for $G$. rostochiensis [Sijmons et al. 1991]). In contrast to $d g t$, lateral root formation was only slightly reduced in these mutants, indicating a lower level of auxin resistance. Only for axr 2 was nematode development significantly reduced (approximately $30 \%$ ) compared with the wild-type cv. Columbia.

In $d g t$, hypertrophy of the feeding cells was negligible (Fig. 2A). For the auxin-resistant Arabidopsis mutants, a similar though less-pronounced reduction in the hypertrophy of the feeding cells was observed compared with syncytia induced on Columbia (Fig. 2G and H). Hypertrophy of the feeding cells was quantified by subtracting the diameter of the vascular bundle in an uninfected part of the root from its maximal diameter at the infection site of adult females. For Columbia, the maximal increase in the diameter of the vascular bundle was $136 \pm 47 \mu \mathrm{m}$ (mean $\pm \mathrm{SD} ; n=7)$. The enlargement of the vascular bundle was reduced to $86 \pm 9 \mu \mathrm{m}(n=2)$ for the auxin-insensitive mutant axrl-3, $43 \pm 23 \mu \mathrm{m}(n=4)$ for axrl$12,101 \pm 53 \mu \mathrm{m}(n=3)$ for $\operatorname{axr} 2,101 \pm 28 \mu \mathrm{m}(n=3)$ for axr4-2, $99 \pm 47 \mu \mathrm{m}(n=2)$ for aux 1-7/axr4-2, and $89 \pm 19 \mu \mathrm{m}$ $(n=4)$ for the auxin influx carrier mutant auxl-7. 
Upon infection of Arabidopsis wild-type roots (Columbia), lateral roots were formed at the infection site within 5 dpi (1.9 \pm 1.5 lateral roots per feeding cell [mean $\pm \mathrm{SD} ; n=7]$ ). Lateral root formation is stimulated by auxin; therefore, this phenomenon provides additional indications for the role of auxin in feeding cell development. In the auxin-insensitive mutant axr4-2 and the double mutant axr1-3/axr4-2, lateral root formation was completely absent at the infection site, whereas the number of lateral roots was halved in feeding sites induced in the mutants axrl-3 (0.5 $\pm 0.7 ; n=2), \operatorname{axr} 1-12(0.25 \pm 0.5 ; n=$ 4), $\operatorname{axr} 2(0.7 \pm 1.2 ; n=3)$, axr4-1 (1.0 $\pm 0.8 ; n=8)$, auxl-7 $(0.75 \pm 0.7 ; n=4)$, and auxl-7/axr4-2 $(1.0 \pm 1.4 ; n=2)$.

\section{Transcriptional activation of an auxin-responsive promoter in early feeding cell development.}

To study local changes in auxin action upon beet cyst nematode infection, the Arabidopsis promoter trap line 826 was used. The promoter- $\beta$-glucuronidase (GUS) fusion in this line is expressed in proliferating tissues and is activated in the root pericycle after exogenous application of auxin. No activation of GUS expression was observed in response to other phytohormones (D. Weijers, M. E. I. Franke-van Dijk, R. J. P. G. Vencken, A. Quint, P. J. J. Hooykaas, and R. Offringa, manuscript in preparation). In both infected and control roots, GUS expression was observed in the root apex and lateral root primordia. Upon infection, transcriptional activation of the gusA reporter gene was observed only during early feeding cell development ( 1 to $8 \mathrm{dpi}$ ) with strongest gusA expression at 3.5 to 4.5 dpi (Fig. 2I). GUS staining was specifically localized in expanding syncytia and in cells surrounding the syncytia. The majority of these neighboring cells will be incorporated in the syncytium at a later stage of feeding cell development. Activation of the promoter was also observed in lateral root primordia formed upon infection (Fig. 2J and K). No GUS activity was detected in the cortex, epidermis, or vascular bundle around this nematode infection site. GUS expression was not induced by mechanical wounding of the roots (data not shown) or nematode migration. It is suggested that early transient activation of the gusA gene reflects cell proliferation triggered by a local increase in the auxin concentration, directly or indirectly induced by the infective juvenile.

\section{Inhibition of polar auxin transport reduces feeding cell development.}

To investigate the role of polar auxin transport in feeding cell development, tomato seedlings were exposed to $1 \mu \mathrm{M}$ phytotropin NPA. Subsequently, roots were inoculated with the potato cyst nematode $G$. rostochiensis. In primary roots treated with NPA, feeding cell formation coincided with extreme galling and numerous swollen root hairs (Fig. 2L). This phenomenon was not observed in uninfected NPA-treated roots (data not shown). A delay in nematode development was noticed, as well as a reduction of approximately $60 \%$ in the number of adult females compared with untreated control roots (data not shown). Alternatively, the phytotropin triiodobenzoic acid (TIBA) was applied, but this inhibitor appeared to be toxic for potato cyst nematodes. The same holds true for $3,3^{\prime}, 4^{\prime}, 5,7$-pentahydroxyflavone (quercetin), which belongs to a different class of auxin transport inhibitors, the flavonoids.

To investigate the effect of impaired polar auxin transport on feeding cell development, the abnormal feeding sites were sectioned. In the interaction tomato-G. rostochiensis, the initial syncytial cell is localized in the cortex and expansion involves the formation of a "cortical bridge" toward the stele (Fig. 2M). Cross sections revealed that NPA treatment hampers the formation of this cortex bridge. Especially when feeding cells are induced in the outer cortex, this radial expansion pattern of the syncytium was seriously restricted (Fig. $2 \mathrm{~N}$ and O). Longitudinal sections showed that feeding cell expansion in a linear direction was not affected by $1 \mu \mathrm{M}$ NPA (data not shown). The gall structure around the feeding cells was the result of massive disordered cell divisions in the cortex, loss of tissue structure, hypertrophy of the vascular bundle, and metaxylem differentiation.

As an alternative to exogenous application of inhibitors, the Arabidopsis polar auxin transport mutants aux 1-7, pin1-1/ttg1, and eirl-1 were tested. The first shows a hampered influx of auxin into the cell; in the latter two, the efflux of auxin out of the cell is hampered through a defect in the auxin export carrier. Only the auxin efflux carrier mutants pin1-1/ttgl and eirl-1 showed a significant reduction of 52 and $89 \%$, respectively, in nematode development (Fig. 3). The reduction in nematode development upon NPA treatment of tomato roots and upon infection of the Arabidopsis transport mutants pinl$1 / \operatorname{ttg} 1$ and eirl-1 indicates that polar auxin transport is essential for cyst nematode-induced feeding cell development. Unlike treatment with NPA, no abnormal feeding cell phenotypes were observed.

\section{Arabidopsis ethylene-response mutants point at a role for ethylene in feeding cell development.}

The Arabidopsis mutant eirl-1, which encodes an auxin efflux carrier, is insensitive to ethylene (Roman et al. 1995). In addition, auxin-inducible ethylene production is impaired in $d g t$ (Kelly and Bradford 1986). The same holds true for most of the auxin-insensitive Arabidopsis mutants (Wilson et al. 1990; Abel et al. 1995). To investigate whether there could be a role for ethylene synthesis in feeding cell development, the dominant ethylene-overproducing mutants etol, eto2, and eto 3 from $A$. thaliana were infected with the beet cyst nematode $H$. schachtii (Fig. 2P). The overproduction of ethylene by the host plant resulted in an acceleration of nematode development (data not shown) and hyperinfection of the roots; $107 \pm$ $32 \%$ (mean $\pm \mathrm{SD}$ ) for etol, $174 \pm 23 \%$ for eto 2 , and $191 \pm$ $55 \%$ for eto3, compared with $100 \%$ nematode development on Columbia. Moreover, the adult females were larger compared with the females grown on control roots (a diameter of $422 \pm$ $71 \mu \mathrm{m}[n=4]$ for etol, $442 \pm 87 \mu \mathrm{m}[n=3]$ for eto 2 , and 452 $\pm 60 \mu \mathrm{m}[n=4]$ for eto 3 versus $371 \pm 26 \mu \mathrm{m}[n=7]$ for Columbia). In cross sections of infected eto 2 roots, the syncytia showed extensive cell wall dissolution and expansion. The remaining cell wall fragments were thickened (Fig. 2Q and $\mathrm{R})$. Enhanced cell wall breakdown in these ethylene mutants suggests that ethylene-induced cell wall degradation is involved in syncytium development.

\section{DISCUSSION}

\section{Feeding cell induction is mediated by auxin.}

Auxin-insensitive mutants from tomato and Arabidopsis were used to demonstrate the role of the phytohormone auxin in feeding cell development by two cyst nematode species. 

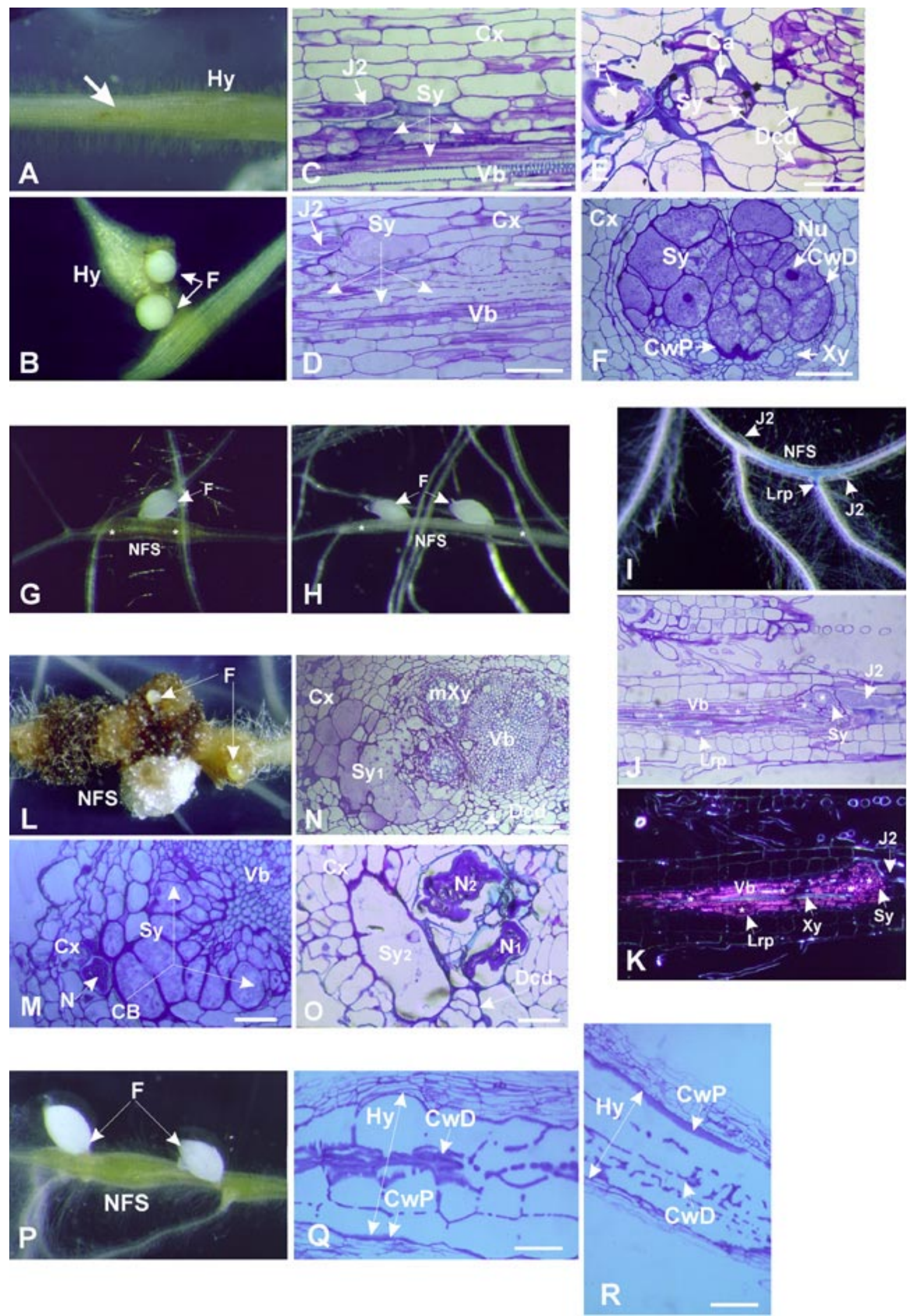
Whereas tomato is an excellent host for the potato cyst nematode $G$. rostochiensis, nematodes did not develop on roots of the extremely auxin-insensitive tomato mutant $d g t$. If lateral root formation is used as an indicator for auxin insensitivity, no equivalent for $d g t$ could be found among the available Arabidopsis mutants. Nevertheless, a significant reduction in the number of developing beet cyst nematodes was observed in the highly auxin-insensitive mutant axr 2 . The auxin-responsive Arabidopsis promoter trap line 826 and polar auxin transport inhibitors were used to gather more information on the role of auxin in feeding cell development.

The failure of potato cyst nematodes to induce normal syncytia in the auxin-insensitive tomato mutant $d g t$ points at a prominent role of auxin in early stages of feeding cell development. These results are supported by experiments with a range of auxin-insensitive Arabidopsis mutants. The rapid and local accumulation of GUS in syncytia of the auxin-responsive promoter trap line 826 from Arabidopsis upon infection with $H$. schachtii suggests a local increase of the auxin concentration or an increased sensitivity toward this phytohormone. A local accumulation of auxin upon feeding cell induction by cyst nematodes is consistent with the substantial decrease in the mRNA levels of the auxin down-regulated genes $a d r-6,-11$, and -12 after infection of soybean roots with H. glycines (Hermsmeier et al. 1998). It is also consistent with

Fig. 2. A-F, Feeding cell formation by the potato cyst nematode Globodera rostochiensis on roots of the auxin-insensitive tomato mutant diageotropica $(d g t)$ and its corresponding background cv. Moneymaker (MM). A, Nematode-infected $d g t$ root 49 days postinoculation (dpi). The migratory track is indicated with an arrow. B, Adult females on an infected control root (MM) at $49 \mathrm{dpi}$. C, Cross section of an infected $d g t$ root at $3 \mathrm{dpi}$. The cytoplasmic content of the feeding cell is completely degraded. D, Cross section of an infected control root (MM) at 6 dpi. E, Cross section of an abnormal feeding cell in roots of $d g t$ at 49 dpi. F, Normal syncytia formation in roots of MM at 49 dpi. G and H, In vitro development of the beet cyst nematode Heterodera schachtii on Arabidopsis thaliana roots. G, Nematode development on the Arabidopsis ecotype Columbia. The feeding sites are indicated with an asterisk. H, Nematode development on roots of the auxin-insensitive Arabidopsis mutant $\operatorname{axr} 2$. I-K, Transcriptional activation of the auxin-responsive promoter 826 in A. thaliana roots upon infection with the beet cyst nematode $H$. schachtii. I, The expression of gus at 4 dpi. J and $\mathbf{K}$, Longitudinal sections showing $\beta$-glucuronidase (GUS) staining (asterisks) in an expanding syncytium and in cells of the vascular bundle that are about to be incorporated into the syncytium. $\mathbf{J}$, The section was stained with toluidine blue. $\mathbf{J}$ and $\mathbf{K}$, The sections were visualized using bright and dark field microscopy, respectively ( $\times 320$ magnification). L-O, Effect of $N$-(1-naphthyl)phtalamic acid (NPA) treatment on potato cyst nematode $(G$. rostochiensis) development in tomato roots. $\mathbf{L}$, Nematode feeding sites in NPA-treated tomato roots (8 weeks post inoculation). M, Cross section of a syncytium in untreated tomato roots. $\mathbf{N}$ and $\mathbf{O}$, Cross sections of syncytia in NPA-treated tomato roots showing an aberrant morphology. P-R, Development of the beet cyst nematode $H$. schachtii on roots of the A. thaliana ethylene response mutant eto2. P, Nematode development on roots of eto 2 at $28 \mathrm{dpi}$. Q, Longitudinal section of a syncytium in eto 2 showing increased cell wall degradation, cell wall deposition, and hypertrophy of the vascular bundle. R, Longitudinal section of a feeding cell induced in roots of the corresponding control cv. Columbia. Abbreviations: $\mathrm{Ca}=$ callose deposit; $\mathrm{CB}=$ cortical bridge; $\mathrm{CwD}=$ cell wall dissolution; $\mathrm{CwP}=$ cell wall protuberances; $\mathrm{Cx}=$ outer cortex; Dcd = disordered cell divisions; $\mathrm{F}=$ young females; $\mathrm{Hy}=$ hypertrophy; $\mathrm{J} 2$ = parasitic second-stage juvenile; Lrp = lateral root primordium; $\mathrm{mXy}=$ metaxylem; $\mathrm{N}=$ nematode NFS = nematode feeding site; $\mathrm{Nu}=$ nucleus; $\mathrm{Sy}=$ syncytium; $\mathrm{Vb}=$ vascular bundle; and $\mathrm{Xy}=$ xylem. A-F, L, M, O-R, Bars $=50 \mu \mathrm{m} ; \mathbf{N}$, Bar $=125 \mu \mathrm{m}$. the activation of the cell cycle genes Arath;cycB1;1 and $c d c 2 a$ in young feeding cells by $H$. schachtii (Niebel et al. 1996; de Almeida-Engler et al. 1999), because both genes are known to be transcriptionally activated by auxin (Doerner et al. 1996; John et al. 1993).

\section{Local auxin gradients affect feeding cell morphology.}

The phytotropin NPA - a noncompetitive auxin efflux inhibitor-severely hampers the directional expansion of the syncytium from the cortex to the stelar tissues and, as a consequence, nematodes developed poorly (60\% reduction). A question arises: Why is the radial proliferation of the syncytium initial toward the vascular cylinder virtually inhibited by NPA? After all, NPA is known to block mainly the acropetal transport of auxin in the stelar tissues and the basipetal transport of indole-3-acetic acid (IAA) in the outer cortex and epidermis. In Arabidopsis, members of a relatively large gene family have been identified encoding PIN (pin-formed) proteins that-most likely - are part of the auxin efflux carrier complex. NPA will (partly) inactivate these PIN-containing complexes. In Arabidopsis roots, AtPIN2 was detected in cor-

Table 1. List of the Arabidopsis thaliana auxin and ethylene response mutants used for infection with the beet cyst nematode Heterodera schachtii

\begin{tabular}{lll}
\hline Mutant & Ecotype & \multicolumn{1}{c}{ Reference } \\
\hline axr1-3/axr1-12 & Col-0 & Estelle and Sommerville 1987 \\
axr2 & Col-0 & Wilson et al. 1990 \\
axr4-1 & Col-0 & Hobbie and Estelle 1995 \\
axr4-2 & Col-0 & Hobbie and Estelle 1995 \\
axr1-3/axr4-2 & Col-0 & Hobbie and Estelle 1995 \\
aux1-7 & Col-0 & Pickett et al. 1990 \\
aux1-7/axr4-2 & Col-0 & Hobbie and Estelle 1995 \\
pin1-1/ttg-1 & Enkheim & Goto et al. 1991 \\
eir1-1 & Col-0 & Roman et al. 1995 \\
eto1-1 & Col-0 & Guzman and Ecker 1990 \\
eto2 & Col-0 & Kieber et al. 1993 \\
eto3 & Col-0 & Kieber et al. 1993 \\
\hline
\end{tabular}

${ }^{a}$ pin 1-1/ttg-1 is a double mutant of pin 1-1 and the unrelated ttg-1. The single pin 1-1 mutant was not available for this study.

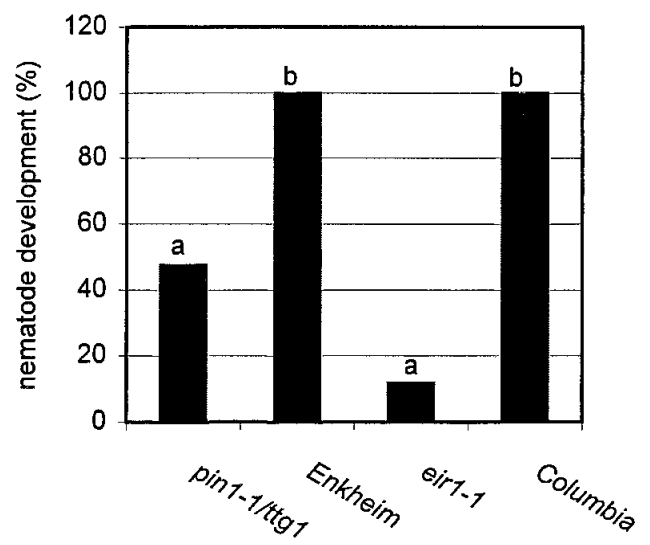

Fig. 3. Development of the beet cyst nematode Heterodera schachtii on roots of the Arabidopsis thaliana transport mutants pin1-1/ttg1 and eir1-1 and the corresponding controls Enkheim and Columbia (6 weeks postinoculation). Infection was significantly reduced for mutants pin1-1/ttg1 and eir $1-1$ with $52 \%(P<0.05)$ and $89 \%(P<0.01)$, respectively. Significant differences between the infection rates-indicated with a and $b-$ were determined using a two-sample $t$ test $(\alpha=0.05)$. 
tical and epidermal cells only. Immunocytological analysis indicated the presence of AtPIN2 at both the anti- and periclinal sides of cortical cells (Müller et al. 1998). This finding would implicate that-apart from basipetal transport of IAAauxin is redistributed from the inner cortex toward the epidermis. As a result, a negative auxin gradient would be created from the epidermis toward the inner cortex. Application of NPA disrupts radial auxin gradients in roots of Arabidopsis (Muday et al. 1995; Ruegger et al. 1997); therefore, it probably affects the AtPIN2-containing auxin efflux carrier complex. If the homologue of AtPIN2 in tomato would have a localization pattern similar to that of AtPIN2 in Arabidopsis, NPA treatment would disturb a radial auxin gradient in the tomato cortex as well. In that case, our results indicate that radial proliferation of young syncytia toward the vascular cylinder follow an auxin gradient. This conclusion is not necessarily supported by inoculation studies with the Arabidopsis polar auxin transport mutants pin1-1/ttgl and eirl-1 (the EIRl gene is identical to AtPIN2). Nematode development was strongly reduced in mutants pin $1-1 /$ ttgl and eirl-1 ( -52 and $-89 \%$, respectively). However, the morphology of the few feeding cells formed was apparently normal. This was expected for the pin1-1/ttg1 mutant because the AtPIN1 protein is present only in the vascular tissues (Gälweiler et al. 1998). However, we can not explain why - though at a low frequency - an apparently normal feeding cell can be formed in tissues harboring a (partially) inactive AtPIN1 protein.

\section{Mechanisms underlying nematode-induced disturbances} of the auxin household in relation to feeding cell induction.

At least two mechanisms can be envisaged that could underlie the local disturbance of the IAA balance in cyst nematodeinfected roots.

In the first mechanism, the infective juveniles themselves could produce and secrete auxin or a homologue of this phytohormone. The initial syncytial cell would experience a high auxin concentration because infective juveniles would release IAA or IAA-like compounds in or around this selected plant cell.

The hypothesis that plant-parasitic nematodes disturb plant tissues by secreting auxins is relatively old. Goodey (1948) hypothesized that "Anguillulina balsamophila" (= Anguina balsamophila) caused galls in the leaves of its host by auxin or auxin-like secretions. Bird (1962) and Yu and Viglierchio (1964) used an auxin bioassay to analyze extracts from root knot nematode-infected plant tissues. In addition, Johnson and Viglierchio (1969) used a similar approach to determine auxin activity in extracts of infective juveniles of the beet cyst nematode $H$. schachtii. In both cases, the presence of auxin or auxin-like substances of nematode origin was claimed. We could not confirm these findings by directing a monoclonal antibody against IAA and its precursor indole-3-acetamide (8-1C10) (Boonekamp et al. 1990). Upon conjugation of free IAA to larger proteins with ethyl-3-(-3dimethylaminopropyl)-carbodiimidehydrochloride (EDC) (DrissEcole and Perbal 1987) and the detection of synthetic IAA on Western blot, no IAA could be detected in the homogenates of approximately 2,000 preparasitic $\mathrm{J} 2$ of G. rostochiensis (data not shown). Therefore, either no auxin is produced by infective juveniles or IAA is present at very low concentrations.

Recently, the effect of cyst nematode secretions on the proliferation of tobacco leaf protoplasts was tested. Potato root diffusate-induced secretions were shown to contain a mito- genic peptide (or peptides) that costimulates the proliferation of protoplasts in the presence of auxin and cytokinin (Goverse et al. 1999). However, unfractionated secretions did not affect the experienced auxin or cytokinin concentration. It is concluded that the local disturbance of the auxin balance in the plant root is probably not caused by the production and secretion of IAA or IAA-homologues by infectious stages of this nematode.

In the second mechanism, a local increase in the auxin concentration could also be realized by stimulating the influx or inhibiting the efflux in a particular cell. Polar auxin transport occurs in cell files and this particularity makes auxin accumulation by local transport inhibition a practicable option. Though auxin can be synthesized in the roots (Müller et al. 1998), the shoot apex is considered to be the main site of IAA production (Morris et al. 1969) and transport from the shoot toward the root tips occurs within the vascular bundle (acropetal transport). From the root tip, auxin is transported upward via cell files in the epidermis or the outer cortex (basipetal transport). In its protonated form, auxin can enter an individual plant cell freely. Alternatively, auxin can be taken up by an influx carrier. Efflux carriers present in the opposite plasma membrane mediate IAA export out of the cell (reviewed by Estelle 1996 and Leyser 1999).

Like feeding cell induction by potato cyst nematodes, nodule formation by rhizobia is accompanied by the mitotic reactivation of clusters of cortical cells. In the Rhizobium spp.legume interaction, nodule formation is preceded by a local increase in the auxin concentration (Mathesius et al. 1998b). Recently, it was determined that flavonoids, which are able to inhibit polar auxin transport in the roots by blocking the auxin efflux carriers, accumulate upon nodule formation. Hence, it is suggested that this causes a local increase of the auxin concentration. In addition, it is proposed that flavonoids and flavonoid glycosides could modulate auxin levels by changing the turnover of auxin (Mathesius et al. 1998a). Recently, Hutangura et al. (1999) reported the reactivation of three chalcone synthase (CHS1, CHS2, and CHS3) promoters in white clover upon infection by root knot nematodes. Hence, gall formation by root knot nematodes also seems to be associated with the activation of the flavonoid pathway.

Currently, the hypothesis that cyst nematodes induce a local accumulation of IAA by blocking auxin efflux carriers is the most appealing explanation for the observed phenomena.

\section{Cross talk between auxin and ethylene in relation to feeding cell morphogenesis.}

Cross talk between different hormones is a common phenomenon in plants and this holds true for auxin and ethylene as well. ACC synthase (ACS), a key enzyme of ethylene biosynthesis, is encoded by a multigene family, which is subdivided into three groups (Oetiker et al. 1997). The expression of group III ACC synthases is controlled by auxin. As a result, the tomato mutant $d g t$ shows a reduced expression of the auxin-induced ACC synthase genes (Abel and Theologis 1996). Similarly, the expression of ACS4 is reduced in the auxin-insensitive Arabidopsis mutants axr1-3, axr1-12, axr2, and aux 1-7 (Abel et al. 1995). As such, a reduction in ethylene production could contribute to the observed defects in syncytium development.

Inoculation of the ethylene-overproducing Arabidopsis mutants etol, eto2, and eto3 with $H$. schachtii resulted in hyper- 
infection and enhanced female development. The ethylene production by the mutant seedlings is 10,20 , and 100 times the production by wild-type seedlings (Kieber et al. 1993) and the increasing $\mathrm{C}_{2} \mathrm{H}_{2}$ levels nicely correlated with increasing numbers of females, which were larger in size and connected to more extensive syncytia compared with the control plants. Protoplasts fusion by cell wall dissolution was promoted in ethylene-overproducing mutants. In this respect, syncytium formation seems to have characteristics in common with ethylene-mediated cell wall degradation during fruit ripening (Gray et al. 1992, 1994; Metha and Mattoo 1995).

Another relevant example of cross talk between auxin and ethylene is the Arabidopsis mutant eirl-1, which is insensitive to ethylene and to the phytotropins TIBA and NPA. EIRI encodes an auxin efflux carrier (EIR1 = AtPIN2) (Luschnig et al. 1998), which suggests that ethylene is involved in the regulation of polar auxin transport. This is supported by the observation that eirl acts downstream of eto 3 or in a pathway parallel to that in which eto3 functions. In this article, it is demonstrated that the efflux carrier EIR1/PIN2 is involved in feeding cell development. The drastic reduction of the infection rate $(-89 \%)$ could be the combined result of difficulties to form a cortical bridge (related to auxin transport inhibition) and the inability of the syncytium to expand due to the ethylene insensitivity of the tissue.

Using three different approaches, strong indications are provided for a crucial role of auxin (and, in its wake, ethylene) in feeding cell induction and morphogenesis by the cyst nematodes $G$. rostochiensis and $H$. schachtii. The most parsimonious explanation for our results is that syncytium development is accompanied by a nematode-induced, local increase of the auxin concentration. As a secondary effect, this IAA accumulation will result in an increased ethylene production. Among other things, this would locally activate plant cell wall degrading enzymes involved in syncytium proliferation. For decades, there has been much speculation on the role of phytohormones in feeding cell formation by endoparasitic nematodes (Giebel 1974, 1982). In this article, we present a set of data all pointing to a crucial role for auxin (and auxin-dependent ethylene) in feeding cell induction by cyst nematodes.

\section{MATERIALS AND METHODS}

\section{Plant material.}

Seed from the tomato mutant $d g t / d g t$ and its corresponding background Lycopersicon esculentum cv. Moneymaker, kindly provided by M. Koornneef (Department of Genetics, Wageningen Agricultural University, The Netherlands), were surfacesterilized in $0.8 \%$ (wt/vol) commercial bleach for $25 \mathrm{~min}$. After rinsing three times with an excess of sterile water, seed were transferred to agar plates containing Murashige and Skoog culture medium supplemented with 2\% sucrose (MS20). Plants were grown at $24^{\circ} \mathrm{C}$ with $16 \mathrm{~h}$ of light. For in vitro nematode infections, tomato stem cuttings were cultured on $1.5 \%$ agar plates (Difco Laboratories, Detroit, U.S.A.) prepared with Gamborg's B5 medium (including vitamins and minerals, $\mathrm{pH}$ 6.2 ) supplemented with $2 \%$ sucrose. For in vivo experiments, individual plants were grown in $600-\mathrm{ml}$ pots (filled with sandy loam soil) at $18^{\circ} \mathrm{C}$ with $16 \mathrm{~h}$ of light.

The A. thaliana mutants used in this study (Table 1) and the corresponding ecotypes Landsberg erecta (Ler-1), Columbia
(Col-0), and Enkheim (En-2) were obtained from the Arabidopsis Biological Resource Center (Columbus, OH). Arabidopsis seed of the promoter trap line 826, with a single TDNA insertion, were kindly provided by R. Offringa (Institute for Molecular Plant Sciences, Leiden University, The Netherlands). Arabidopsi seed were surface-sterilized with 5\% (wt/vol) hypochloride and absolute ethanol (4:1, vol/vol) for $10 \mathrm{~min}$, rinsed two times with absolute ethanol, and dried overnight in the flow chamber. Seed were transferred to plates with modified Knop medium as described by Sijmons et al. (1991). Slightly tilted plates were grown at $22^{\circ} \mathrm{C}$ with $16 \mathrm{~h}$ of light.

\section{Cyst nematode inoculation.}

In vitro cultures of tomato were inoculated with preparasitic $\mathrm{J} 2$ of the potato cyst nematode G. rostochiensis Ro1 Mierenbos. Surface-sterilized preparasitic $\mathrm{J} 2$ were obtained from dry cysts according to Heungens et al. (1996). Hatching was promoted by filter-sterile potato root diffusate (Clarke and Perry 1977). After 3 to 5 days, $\mathbf{J} 2$ were collected on a 5 - $\mu \mathrm{m}$-pore-size sieve and surface-sterilized using the following disinfectants: $0.5 \%$ (wt/vol) streptomycin sulfate-penicillin G (20 min), $0.1 \%$ (wt/vol) ampicillin-gentamycin $(20 \mathrm{~min})$, sterile tap water $(5 \mathrm{~min})$, and $0.1 \%$ (vol/vol) chlorhexidin-digluconate (3 min). After washing in sterile tap water, $\mathbf{J} 2$ were suspended and approximately 50 individuals were transferred to 8- to 10-day-old root tips using a pipetman with siliconized tips (Costar Corporation, Cambridge, MA, U.S.A.). When roots were grown under the agar, infection was facilitated by perforating the agar with a sterile glass pipette. Inoculated plates were kept in the dark at $18^{\circ} \mathrm{C}$.

For in vivo nematode infections, preparasitic J2 were obtained from dry cysts of $G$. rostochiensis Ro1 Mierenbos (Roosien et al. 1993). Tomato plants (39 days old) were inoculated with 3,500 preparasitic $\mathrm{J} 2$ and grown at $18^{\circ} \mathrm{C}$ with $16 \mathrm{~h}$ of light. In vitro cultures of 14-day-old Arabidopsis plants were inoculated with sterile preparasitic $\mathrm{J} 2$ of the beet cyst nematode $H$. schachtii. Cysts obtained from monoxenic cultures on mustard (Sinapsis alba), kindly provided by F. Grundler (Institut für Phytopathology, C. Albrechts Universität, Kiel, Germany), were incubated on a $100-\mu \mathrm{m}$-pore-size sieve in $3 \mathrm{mM} \mathrm{ZnCl} 2$ for 5 to 7 days at $25^{\circ} \mathrm{C}$ in order to hatch $\mathrm{J} 2$ (Grundler 1989). J2 were rinsed in sterile tap water and $40 \mathrm{~J} 2$ were used for inoculation as described for in vitro cultures of potato cyst nematodes. Plates were sealed with Nesco film (Carl Roth GmbH \& Co, Karlsruhe, Germany) and incubated in a slightly tilted position at $22^{\circ} \mathrm{C}$ with $16 \mathrm{~h}$ of light.

\section{Analysis of cyst nematode development.}

Nematode development on tomato and Arabidopsis lines (both wild type and mutants) was monitored in vitro using either a binocular or an inverted microscope (magnification $\times 100$ to $\times 250$ ). Normally, root infection by preparasitic J2 results in the formation of a feeding cell. The parasitic J2 subsequently develops into two other juvenile stages, J3 and J4. Four to six weeks postinoculation, adult males and females appear. In this study, nematode development was expressed as the percentage of adult individuals that were able to develop on mutant compared with wild-type roots (the latter defined as $100 \%$ ). For the tomato mutant $d g t$, the intermediate developmental stages also were determined (Fig. 1).

Monitoring nematode development in soil is virtually impossible; therefore, the number of cysts per tomato plant was 
counted 4 months postinoculation. Cysts are the remainders of the female that may enclose hundreds of fertilized eggs. Cysts of individual plants were crushed to determine the number of eggs per cyst. The number of eggs per cyst is indicative of successful nematode development.

\section{Inhibition of polar auxin transport.}

Surface-sterilized seeds of tomato cv. Moneymaker were germinated on plates with MS20 culture medium which were positioned vertically to allow roots to grow on the agar surface. After 10 days, three seedlings were transferred to each plate with Gamborg's B5 medium supplemented with $2 \%$ sucrose and $1 \mu \mathrm{M}$ NPA (Duchefa, Haarlem, The Netherlands). After 1 day, roots were inoculated with surface-sterilized preparasitic J2 of G. rostochiensis. In control experiments, either NPA or the nematodes were omitted. All experiments were repeated twice. Feeding cell and nematode development were observed using a dissecting microscope (Leica, Wetzlar, Germany) and the number of adult females was counted at 8 weeks postinoculation.

\section{Histochemical GUS assay.}

Feeding cell development and the parasitic stage of the nematode were determined prior to tissue preparation using an inverted light microscope (Leica). For each developmental stage $(4,14,24$, and $36 \mathrm{~h}$ postinoculation and 3, 5, 8, and 15 days postinoculation), 5 to 10 plants were examined. Histochemical GUS assay was performed according to Barthels et al. (1997) and GUS staining was observed using bright field and dark field microscopy (Zeiss, Oberkochen, Germany).

\section{Histology of nematode feeding cells.}

Infected roots of tomato and A. thaliana were fixed in $4 \%$ freshly prepared formaldehyde supplemented with $0.25 \%$ glutaraldehyde in phosphate-citrate buffer $(\mathrm{pH} 7.4)$ using a short vacuum infiltration step. Tissues were embedded in LR White resin according to the manufacturer (Aurion BV, Wageningen, The Netherlands) to prepare semithin sections on glass slides. Sections were stained with $1 \%$ toluidine blue and morphology of the feeding cells was observed using light microscopy (Leica).

\section{ACKNOWLEDGMENTS}

We thank M. Koornneef (Laboratory of Genetics, Wageningen University, The Netherlands), F. Grundler (Institut für Phytopathology, C. Albrechts Universität, Kiel, Germany), and R. Offringa (Institute for Molecular Plant Sciences, Leiden University, The Netherlands) for providing us with the tomato mutant diageotropica, monoxenic cultures of Heterodera schachtii, and the Arabidopsis promoter trap line 826, respectively. This research was financially supported by a grant from the Dutch Foundation for Life Sciences (SLW-NWO) and the EC grant BIO4-CT96-0318.

\section{LITERATURE CITED}

Abel, S., Nguyen, M. D., Chow, W., and Theologis, A. 1995. Asc4, a primary indoleacetic acid-responsive gene encoding 1-aminocyclopropane-1-carboxylate synthase in Arabidopsis thaliana. J. Biol. Chem. 270:19093-19099.

Abel, S., and Theologis, A. 1996. Early genes and auxin action. Plant Physiol. 111:9-17.

Barthels, N., van der Lee, F., Klap, J., Goddijn, O. J. M., Karimi, M., Puzio, P., Grundler, F., Ohl, S. A., Lindsey, K., Robertson, L., Robertson, W. M., Van Montagu, M., Gheysen, G., and Sijmons, P. C. 1997.
Regulatory sequences of Arabidopsis drive reporter gene expression in nematode feeding structures. Plant Cell 9:2119-2134.

Bird, A. F. 1962. The inducement of giant cells by Meloidogyne incognita. Nematologica 8:1-10.

Böckenhoff, A., and Grundler, F. M. W. 1994. Studies on the nutrient uptake by the beet cyst nematode Heterodera schachtii by in situ microinjection of fluorescent probes into the feeding structures in Arabidopsis thaliana. Parasitology 109:249-254.

Boonekamp, P. M., Pomp, H., Davelaar, E., and Vonk, C. R. 1990. Selection of monoclonal antibodies to the plant growth regulators indole-3acetic acid and abscisic acid after immunization with conjugates coupled through the carboxyl group. Pages 37-45 in: Monoclonal Antibodies in Agriculture. A. Schots, ed. Pudoc Wageningen, the Netherlands.

Clarke, A. J., and Perry, R. N. 1977. Hatching of cyst-nematodes. Nematologica 23:350-368.

De Almeida-Engler, J., De Vleesschauwer, V., Burssens, S., Celenza, J. L., Jr., Inzé, D., Van Montagu, M., Engler, G., and Gheysen, G. 1999. Molecular markers and cell cycle inhibitors show the importance of cell cycle progression in nematode-induced galls and syncytia. Plant Cell 11:793-807.

Doerner, P., Jørgenesen, J.-E., You, R., Steppuhn, J., and Lamb, C. 1996. Control of root growth and development by cyclin expression. Nature 380:520-523.

Doerner, P. W. 1994. Cell cycle regulation in plants. Plant Physiol. 106:823-827.

Driss-Ecole, D., and Perbal, G. 1987. Intracellular localisation of ${ }^{3} \mathrm{H}-$ IAA in the apical bud of Lycopersicon esculentum. J. Exp. Bot. 38: 1362-1372.

Estelle, M. 1996. Polar auxin transport: New support for an old model. Plant Cell 10:1775-1778.

Estelle, M. A., and Sommerville, C. R. 1987. Auxin resistant mutants of Arabidopsis with an altered morphology. Mol. Gen. Genet. 206:200-206.

Gälweiler, L., Guan, C., Müller, A., Wisman, E., Mendgen, K., Yephremov, A., and Palme, K. 1998. Regulation of polar auxin transport by AtPIN1 in Arabidopsis vascular tissue. Science 282:2226-2230.

Giebel, J. 1974. Biochemical mechanisms of plant resistance to nematodes: A review. J. Nematol. 6:175-184.

Giebel, J. 1982. Mechanism of resistance to plant nematodes. Annu. Rev. Phytopathol. 20:257-279.

Goodey, J. B. 1948. The galls caused by Anguillulina balsamophila (thorne) Goodey on the leaves of Wyethia amplexicaulis Nutt and Balsamorizha sagittata. J. Helminthol. 22:109-116.

Goto, N., Kumagai, T., and Koornneef, M. 1991. Flowering responses to light-breaks in photomorphogenic mutants of Arabidopsis thaliana, a long-day plant. Physiol. Plant. 83:209-215.

Goverse, A., Rouppe van der Voort, J., Rouppe van der Voort, C., Kavelaars, A., Smant, G., Schots, A., Bakker, J., and Helder, J. 1999. Naturallyinduced secretions of the potato cyst nematode co-stimulate the proliferation of both tobacco leaf protoplasts and human peripheral blood mononuclear cells. Mol. Plant-Microbe Interact. 12:872-881.

Gray, J., Picton, S., Shabbeer, J., Schuch, W., and Grierson, D. 1992. Molecular biology of fruit ripening and its manipulation with antisense genes. Plant Mol. Biol. 19:69-87.

Gray, J. E., Picton, S., Giovannoni, J. J., and Grierson, D. 1994. The use of transgenic and naturally occurring mutants to understand and manipulate tomato fruit ripening. Plant Cell Environ. 17:557-571.

Grundler, F. M. W. 1989. Untersuchungen zur Geschlechtsdetermination des Rubenzystennematoden Heterodera schachtii Schmidt. Ph.D. thesis. University of Kiel, Germany.

Grundler, F. M. W., Sobczak, M., and Golinowski, W. 1998. Formation of wall openings in root cells of Arabidopsis thaliana following infection by the plant-parasitic nematode Heterodera schachtii. Eur. J. Plant Pathol. 104:545-551.

Grymaszewska, G., and Golinowski, W. 1991. Structure of syncytia induced by Heterodera avenae Woll. in roots of susceptible and resistant wheat (Triticum aestivum L.). J. Phytopathol. 133:307-319.

Guzmán, P., and Ecker, J. R. 1990. Exploiting the triple response of Arabidopsis to identify ethylene-related mutants. Plant Cell 2:513-523.

Hemerly, A. S., Ferreira, P. C. G., de Almeida Engler, J., Van Montagu, M., Engler, G., and Inzé, D. 1993. cdc2a expression in Arabidopsis thaliana is linked with competence for cell division. Plant Cell 5:1711-1723.

Hermsmeier, D., Mazarei, M., and Baum, T. J. 1998. Differential display analysis of the early compatible interaction between soybean and the soybean cyst nematode. Mol. Plant-Microbe Interact. 11:1258-1263. 
Heungens, K., Mugniery, D., Van Montagu, M., Gheysen, G., and Niebel, A. 1996. A method to obtain disinfected Globodera infective juveniles directly from cysts. Fundam. Appl. Nematol. 19:91-93.

Hobbie, L., and Estelle, M. 1995. The axr4 auxin-resistant mutants of Arabidopsis thaliana define a gene important for root gravitropism and lateral root initiation. Plant J. 7:211-220.

Hutangura, P., Mathesius, U., Jones, M. G. K., and Rolfe, B. G. 1999 Auxin induction is a trigger for root gall formation caused by rootknot nematodes in white clover and is associated with the activation of the flavonoid pathway. Aust. J. Plant Physiol. 26:221-231.

John, P. C. L., Zhang, K., Dong, C., Diederich, L., and Wightman, F. 1993. p34 $4^{\text {cdc2 }}$ related proteins in control of cell cycle progression, the switch between division and differentiation in tissue development, and stimulation of division by auxin and cytokinin. Aust. J. Plant Physiol. 20:503-526.

Johnson, R. N., and Viglierchio, D. R. 1969. A growth promoting substance occurring in an extract prepared from Heterodera schachtii larvae. Nematologica 15:159-160.

Jones, M. G. K. 1981. The development and function of plant cells modified by endoparasitic nematodes. Pages 255-279 in: Plant Parasitic Nematodes, Vol. III. B. M. Zuckerman and R. A. Rohde, eds. Academic Press, New York, U.S.A.

Jones, M. G. K., and Northcote, D. H. 1972. Nematode-induced syncytium-A multinucleate transfer cell. J. Cell Sci. 10:789-809.

Kelly, M. O., and Bradford, K. J. 1986. Insensitivity of the diageotropica tomato mutant to auxin. Plant Physiol. 82:713-717.

Kieber, J. J., Rothenberg, M., Roman, G., Feldman, K. A., and Ecker, J. R. 1993. CTR1, a negative regulator of the ethylene response pathway in Arabidopsis, encodes a member of the raf family of protein kinases. Cell 72:427-441.

Leyser, O. 1999. Plant hormones: Ins and outs of auxin transport. Curr Biol. 9:R8-R10.

Luschnig, C., Gaxiola, R. A., Grisafi, P., and Fink, G. 1998. EIR1, a root-specific protein involved in auxin transport, is required for gravitropism in Arabidopsis thaliana. Genes Dev. 12:2175-2187.

Magnusson, C., and Golinowski, W. 1991. Ultrastructural relationships of the developing syncytium induced by Heterodera schachtii (Nematoda) in root tissues of rape. Can. J. Bot. 69: 44-52.

Mathesius, U., Bayliss, C., Weinman, J. J., Schlaman, H. R. M., Spaink, H. P., Rolfe, B. G., McCully, M. E., and Djordjevic, M. A. 1998a. Flavonoids synthesized in cortical cells during nodule inition are early developmental markers in white clover. Mol. Plant-Microbe Interact. 11:1223-1232.

Mathesius, U., Schlaman, H. R. M., Spaink, H. P., Sautter, C., Rolfe, B. G., and Djordjevic, M. A. 1998b. Auxin transport inhibition precedes root nodule formation in white clover roots and is regulated by flavonoids and derivatives of chitin oligosaccharides. Plant J. 14:23-34

Metha, R. A., and Mattoo, A. K. 1995. Gene expression and protein dynamics during fruit ripening. Pages 343-352 in: Postharvest Physiology, Pathology and Technologies for Horticultural Commodities: Recent Advances. A. Ait-Oubahou and M. El-Otmani, eds. Agadir Marocco, Institut Agronomique et Veterinaire Hassan II.

Morris, D. A., Briant, R. E., and Thomson, P. G. 1969. The transport and metabolism of ${ }^{14} \mathrm{C}$-labeled indoleacetic acid in intact pea seedlings.
Planta 89:178-197.

Muday, G. K., Lomax, T. L., and Rayle, D. L. 1995. Characterization of the growth and auxin physiology of roots of the tomato mutant, diageotropica. Planta 195:548-553.

Müller, A., Guan, C., Gälweiler, L., Tänzler, P., Huijser, P., Marchant, A., Parry, G., Bennett, M., Wisman, E., and Palme, K. 1998. AtPIN2 defines a locus of Arabidopsis for root gravitropism control. EMBO J. 17:6903-6911.

Niebel, A., de Almeida Engler, J., Hemerly, A., Ferreira, P., Van Montagu, M., and Gheysen, G. 1996. Induction of $c d c 2 a$ and $c y c 1 A t$ expression in Arabidopsis during early phases of nematode-induced feeding cell formation. Plant J. 10:1037-1043.

Oetiker, J. H., Olson, D. C., Shiu, O. Y., and Yang, S. F. 1997. Differential expression of seven 1-aminocyclopropane-1-carboxylate genes by elicitor in suspension cultures of tomato (Lycopersicon esculentum). Plant Mol. Biol. 34:275-286.

Pickett, F. B., Wilson, A. K., and Estelle, M. 1990. The aux1 mutation of Arabidopsis confers both auxin and ethylene resistance. Plant Physiol. 94:1462-1466.

Roman, G., Lubarsky, B., Kieber, J. J., Rothenberg, M., and Ecker, J. R. 1995. Genetic analysis of ethylene signal transduction in Arabidopsis thaliana: Five novel mutant loci integrated into a stress response pathway. Genetics 139:1393-1409.

Roosien, J., Van Zandvoort, P. M., Folkertsma, R. T., Rouppe van der Voort, J. N. A. M., Goverse, A., Gommers, F. J., and Bakker, J. 1993 Single juveniles of the potato cyst nematodes Globodera rostochiensis and G. pallida differentiated by randomly amplified polymorphic DNA. Parasitology 107:567-572

Ruegger, M., Dewey, E., Hobbie, L., Brown, D., Bernasconi, P., Turner J., Muday, G., and Estelle, M. 1997. Reduced naphthylphtalamic acid binding in the tir3 mutant of Arabidopsis is associated with a reduction in polar auxin transport and diverse morphological defects. Plant Cell 9:745-757.

Scheres, B., Sijmons, P. C., Van den Berg, C., McKhann, H., De Vrieze, G. Willemsen, V., and Wolkenfelt, H. 1997. Root anatomy and development, the basis for nematode parasitism. Pages 25-37 in: Cellular and Molecular Aspects of Plant-Nematode Interactions. C. Fenoll, F. M. W. Grundler, and S. A. Ohl, eds. Kluwer Academic Publishers, Dordrecht, The Netherlands.

Sijmons, P. C., Grundler, F. M. W., von Mende, N., Burrows, P. R., and Wyss, U. 1991. Arabidopsis thaliana as a new model host for plantparasitic nematodes. Plant J. 1:245-254.

Sijmons, P. C., von Mende, N., and Grundler, F. M. W. 1994. Plantparasitic nematodes. Pages 749-767 in: Arabidopsis. Cold Spring Harbor Laboratory Press, Cold Spring Harbor, NY, U.S.A

Williamson, V. M., and Hussey, R. S. 1996. Nematode pathogenesis and resistance in plants. Plant Cell 8:1735-1745.

Wilson, A. K., Pickett, F. B., Turner, J. C., and Estelle, M. 1990. A dominant mutation in Arabidopsis confers resistance to auxin, ethylene and abscisic acid. Mol. Gen. Genet. 222:2-3, 377-383.

Yu, P. K., and Viglierchio, D. R. 1964. Plant growth substances and parasitic nematodes. I. Root knot nematodes and tomato. Exp. Parasitol. 15: 242-248.

Zobel, R. W. 1974. Control of morphogenesis in the ethylene-requiring tomato mutant, diageotropica. Can. J. Bot. 52:735-741 